\title{
Determination of Methylene blue Number to Characterize the Lapsi Based Activated carbon Prepared by Chemical Carbonization
}

\author{
Rajeshwar Man Shrestha \\ Department of Applied Sciences, Institute of Engineering, Tribhuvan University, Nepal \\ Corresponding author: rajeshwar@ioe.edu.np
}

Received: Nov 6, 2018

Revised: Dec 28, 2018

Accepted: Jan 2, 2019

\begin{abstract}
Determination of Methylene blue Number of the activated carbons prepared by Chemical Carbonization from waste material, seed stone of Lapsi has been studied. Methylene blue Number has been determined by single point method using batch adsorption method. Acids like concentrated sulphuric acid and a mixture of concentrated sulphuric acid and concentrated nitric acid have been used to prepare activated carbon. The activated carbon prepared by using a mixture of concentrated sulphuric acid and concentrated nitric acid has been found to have higher methylene blue number than the activated carbon prepared by using concentrated sulphuric acid. The activated carbons thus prepared can be used as effective adsorbents for the remediation of pollutants from water.
\end{abstract}

Key words: Activated carbon, Lapsi seed stone, chemical carbonization, Nitric acid, Sulphuric acid

\section{Introduction}

Activated carbons are highly porous materials which have been widely used in the adsorption of pollutants in gaseous phase or liquid phase. Many waste materials such as agricultural wastes, fruit stones, hard shell of fruit stones, bagasse, manure compost, oil palm waste, agriculture residue from sugarcane, saw dust, sewage sludge [5] have been widely used for preparation of activated carbon. Activated carbons are generally prepared by a two-stage process carbonization followed by activation. Carbonization process causes to enrich carbon content and create initial porosity while activation helps to enhance the pore structure [8].The activation process can be done by two different methods physical activation and chemical activation. Many studies have shown the use of low cost wastes and agricultural by- products such as black stone cherries [4], peach stones [2], orange peel [3], Peanut shell [9] for production of activated carbon to provide economic solution.

Lapsi seed stone is the waste product of Lapsi fruits. Lapsi (Choerospondias axillaris) is a large, fruit bearing deciduous tree native to the hills of Nepal $(865-1900 \mathrm{~m})$. Lapsi fruit is consumed fresh, pickled or processed into a variety of sweet and sour fruit products locally called "Mada" or"Titaura". It is a rich source of vitamin C. It is also believed to help in digestion and is often consumed after a protein rich meal. Seed stones are used as fuel in brick kilns in the factories and the trunk of the tree is used as fuel wood and timber [6]. The aim of this work is to determine 
methylene blue number of activated carbons prepared from Lapsi seed stone by chemical carbonization with concentrated sulphuric acid and a mixture of concentrated sulphuric acid and concentrated nitric acid. The carbonization carried out by treatment with chemicals is termed as chemical carbonization.

The information about the structure of activated carbons can be obtained by the adsorption characteristics of different adsorbates, such as methylene blue and iodine. Methylene blue is a synthetic cationic thiazine dye with a molecular formula $\mathrm{C}_{16} \mathrm{H}_{18} \mathrm{ClN}_{3} \mathrm{~S} \cdot \mathrm{XH}_{2} \mathrm{O}$ [1]. It is also called basic blue 9, tetramethylthionine chloride. The methylene blue number is defined as the maximum amount of dye adsorbed on $1.0 \mathrm{~g}$ of adsorbent. Adsorption experiments of the molecules of methylene blue are easy and habitually done to characterize activated carbons with the purpose of obtaining information on the adsorption capacity of the materials. According to the dimensions of the methylene blue molecule, it is mainly adsorbed in mesopores, however, a small portion is also found in larger micropore.

\section{Material and Methods}

The precursors used for the preparation of activated carbons in current study are Seed stones of Lapsi fruits which were collected from Kalimati market, Kalimati, Kathmandu. The seed stones were washed several times using tap water and then distilled water to remove impurities, dried at $110^{\circ} \mathrm{C}$ for 24 hours and crushed with mortar and grinded with electric grinder. The seed particles were divided into two parts. One part of the Lapsi seed particles were treated with concentrated $\mathrm{H}_{2 \mathrm{SO} 4}$ in 1:1 weight ratio and kept in an oven maintained at a temperature of $150{ }^{\circ} \mathrm{C}$ for 24 hours distilled water. The particles were then washed with distilled water till the $\mathrm{pH}$ and conductivity of the washing were equal to that of distilled water. The particles were dried in an oven at $110^{\circ} \mathrm{C}$ for 12 hours. The particles were then ground and sieved to get the particles size of $100 \mu \mathrm{m}$. The carbon has been named as AC-1

Another part of the Lapsi seed particles were treated with concentrated $\mathrm{H}_{2 \mathrm{SO} 4}$ in 1:1 weight ratio. The mixture was then treated with conc. $\mathrm{HNO}_{3}$ for further oxidation and was kept in an oven at 150 ${ }^{\circ} \mathrm{C}$ or 24 hours. The dried mixture was washed with distilled water till the $\mathrm{pH}$ and conductivity of the washing were equal to that of distilled water. The acid free sample was dried, ground and then sieved to the particle size of $100 \mu \mathrm{m}$. The carbon has been named as AC-2

\subsection{Chemical and Instrument}

Methylene blue used was of analytical grade (Qualigens Company). The adsorption experiments were carried out by using Shaker (Digital VDRL Rotator-RPM-S). All the working solutions were prepared by diluting the stock solutions with distilled water.

\subsection{Adsorption Experiments}

Methylene blue number of activated carbons has been determined by stirring $0.05 \mathrm{~g}$ of activated carbon with $100 \mathrm{~mL}$ of MB concentration of $100 \mathrm{ppm}$ for 3 hours at $200 \mathrm{rpm}$. The solution was then filtered through Whatman 41 filter paper and the remaining concentration of methylene blue was determined by measuring the absorbance at $664 \mathrm{~nm}$ using a UV/ Visible spectrophotometer (CECIL- CE-100). Methylene blue number was calculated by the following equation [7]

$$
\mathrm{MB}_{\mathrm{N}}\left(\frac{\mathrm{mg}}{\mathrm{g}}\right)=\frac{\left(\mathrm{C}_{\mathrm{o}}-\mathrm{C}_{\mathrm{e}}\right) \times \mathrm{V}}{\mathrm{M}}
$$


where $\mathrm{C}_{\mathrm{o}}$ and $\mathrm{C}_{\mathrm{e}}$ are initial and equilibrium concentration of $\mathrm{MB}(\mathrm{mg} / \mathrm{L})$ respectively, $\mathrm{M}$ is the mass of adsorbent in gram $(\mathrm{g})$ and $\mathrm{V}$ is the volume of the solution in liter $(\mathrm{L})$ and $\mathrm{MB}_{\mathrm{N}}$ is Methylene blue number.

\section{Results and Discussion}

Activated carbons were prepared from Lapsi (Choerospondias axillaris) seed stone by chemical carbonization with concentrated sulphuric acid and a mixture of concentrated sulphuric acid and concentrated nitric acid. The activated carbons thus prepared are characterized by Methylene blue number.

\subsection{Effect of Concentrated Sulphuric Acid}

Methylene blue number gives information about the mesopores of activated carbon. Concentrated sulphuric acid being as a powerful oxidizing agent, the elements such as $\mathrm{C}, \mathrm{H}$ present in the precursor were oxidized into compounds which escape by making pores. Similarly the acid being as a strong dehydrating agent removes water molecules from the waste products by creating pores. So the treatment with concentrated sulphuric acid has created pores such as micropores and mesopores.

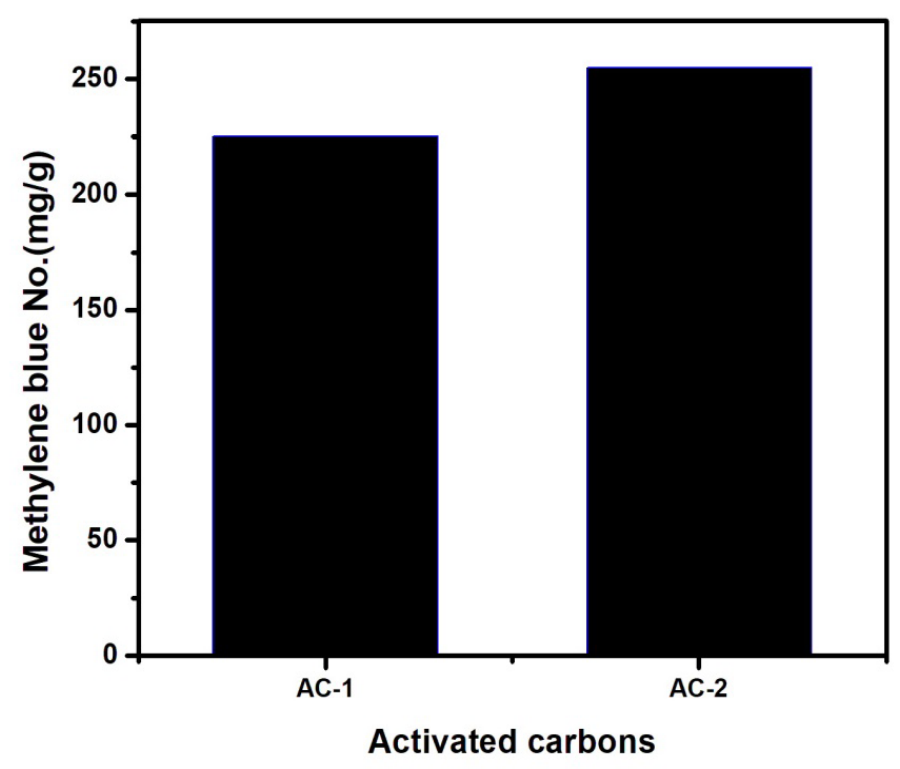

Fig 1: Methylene blue No. of Activated Carbons

\subsection{Effect of a Mixture of Concentrated Sulphuric Acid and Concentrated Nitric Acid}

The activated carbon prepared by treatment with the mixture of concentrated sulphuric acid and concentrated nitric acid has been found to have higher methylene blue number than the activated carbon prepared by using concentrated sulphuric acid. This may be due to the fact that the use of two concentrated acids show as dehydrating as well as double oxidizing behaviors, so more oxidization of the elements present in the precursor to more gaseous products creates more pores than that in former activated carbon. 


\section{Conclusion}

Characterization of the Activated carbons from Lapsi seed stone prepared by chemical carbonization with treatment with concentrated sulphuric acid and a mixture of concentrated sulphuric acid and concentrated nitric acid has been studied. Methylene blue No. has been determined by single point method using batch adsorption method. The activated carbon prepared by using a mixture of concentrated sulphuric acid and concentrated nitric acid has been found to have higher methylene blue number than the activated carbon prepared by using concentrated sulphuric acid. The activated carbons thus prepared can be used as effective adsorbents for the remediation of pollutants from water.

\section{References}

[1] Atef S. ALzaydien (2009), Adsorption of Methylene blue from Aqueous Solution onto a Lowcost Natural Jordanion Tripoli, American Journal of Environmental Sciences, 5 (3): 197-208.

[2] Dong SK (2004), Activated Carbon from Peach Stones Using Phosphoric Acid Activation at Medium Temperatures, Journal of Environmental Science and Health, 39(5) 1301-1318.

[3] Foo KY and Hameed BH (2002), Preparation, Characterization and evaluation of adsorptive properties of orange peel based activated carbon via microwave induce $\mathrm{K}_{2} \mathrm{CO}_{3}$ activation, Bioresource Technology, 104: 679- 689.

[4] Maria JR, Arana R and Mazzoco R (2010), Adsorption studies of methylene blue and phenol onto black stone cherries prepared by chemical activation, Journal of Hazardous Maetrials, 180: 656-661.

[5] Mohammadi SZ, Karimi MA, Afzali D and Mansouri F (2010), Removal of Pb (II) ions from aqueous Solution using activated carbon from Sea buckthorn by chemical activation, Desalination, 263: 83-93.

[6] Paudel KC and Parajuli DP (1999), Domestication and Commercialization of Lapsi tree: potential income source through agroforestry in the middle hills of Nepal, Scientific World, Nepal 1(1): $116-120$.

[7] Raposo F, De La Rubia MA and Borja R (2009), Methylene blue number as useful indicator to evaluate the adsorptive capacity of granular activated carbon in batch mode: Influence of adsorbate/adsorbent mass ratio and particle size, Journal of Hazardous Materials, 165: 291-299.

[8] Shrestha RM (2016), Effect of Preparation Parameters on Methylene blue Number of Activated carbons Prepared from a Locally Avaialble Material, Journal of the Institute of Engineering, 12(1) : 169-174.

[9] Tau X and Xiaoqin L (2008), Peanut shell Activated Carbon: Characterization, Surface Modification and Adsorption of $\mathrm{Pb}^{+2}$ from Aqueous Solution, Chinese Journal of Chemical Engineering, 16(3): 401- 406. 